\title{
CRYOGLOBULINS AND PYROGLOBULINS: AN OVERVIEW
}

\author{
Franco Dammacco *, Antonio Miglietta **, Giovanni Lobreglio **, \\ LORENZO BONOMO *** \\ Istituto di Patologia Medica *, Università degli Studi di Bari \\ Istituto di Clinica Medica II ${ }^{* *}$, Università degli Studi di Bari \\ Istituto di Clinica Medica III ${ }^{* * *}$, Università degli Studi di Roma
}

In 1933 WINTROBE and BUELL ${ }^{88}$ described a case of multiple myeloma in a 56-year-old woman whose serum formed a precipitate when cooled, that redissolved when the serum was warmed to $37^{\circ} \mathrm{C}$. The patient had hepatosple. nomegaly, Raynaud's phenomenon, purpura, as well as venous thrombosis of the retina. In 1941 PETERS and HoRTON ${ }^{66}$ reported on a patient with 'allergic purpura' that appeared after exposure to cold. The patient, a 53-year-old man living in Minnesota, wore heavy clothes even on mild days, since exposure to cold induced purpura, urticaria and arthralgia. Desensitization with histamine did not help, but his symptoms decreased when he moved to the much warmer climate of Arizona. Three years later he was seen at the University of Minnesota by LERNER and WATSON ${ }^{45}$, who detected in his serum a protein that precipitat. ed in the cold, characterized it as a gammaglobulin and named it cryoglobulin.

\section{DEFINITION AND CLASSIFICATION}

Cryoglobulins are presently defined as a group of serum proteins with temperature-dependent solubility. While most proteins are highly soluble and remain in solution in the cold up to concentrations above $100 \mathrm{mg} / \mathrm{ml}$, cryo. globulins precipitate or form a gel below $37^{\circ} \mathrm{C}$, even at concentrations of 0.1 $\mathrm{mg} / \mathrm{dl}^{14,21,55}$. The temperature at which they precipitate is a function of their concentration, the higher the concentration the higher the temperature of precipitation. At low concentrations they precipitate only around $4{ }^{\circ} \mathrm{C}$ and completely redissolve when the serum is reheated to $37^{\circ} \mathrm{C}$. The $\mathrm{pH}$ of the solution is also important for cryoprecipitation ${ }^{36}$. Usually cryoprecipitation does not occur at $\mathrm{pH}$ below 5.0 or above 8.0 .

Key-words: Cryoglobulins; Fibronectin; Immune complexes; Immunoglobulins; Pyroglobulins; Rheumatoid factor.

La Ricerca Clin. Lab. 16, 247, 1986. 
It should be emphasized that small amounts of cryoglobulin may occur in human serum normally, in concentrations of about $30 \mu \mathrm{g} / \mathrm{ml}$ ". Therefore, cryoglobulins should be considered to be abnormal increases in proteins normally present in serum in relatively small amounts.

The etiological heterogeneity of the cryoglobulins is suggested by the fact that cryoproteins have been described in patients with many different diseases ${ }^{33}$ (tab. 1). Cryoglobulinemia associated with one of these diseases is called secondary cryoglobulinemia, whereas patients for whom no associated pathology can be found are said to have essential or idiopathic cryoglobulinemia. This last form is known as the LoSpalluto-Meltzer syndrome and is characterized by a triad of symptoms, namely purpura, arthralgia and weakness. Renal failure often follows these.

For several years it has been thought that most, if not all, cryoglobulins are immune complexes ${ }^{21}$ made up of antigen $(\mathrm{Ag})+$ antibody (Ab), sometimes also combined with complement. This hypothesis was confirmed by studying the immunochemical properties of several cryoproteins, by showing their frequent occurrence in diseases associated with immune complexes and by detecting the deposition of immune complexes in different organs and tissues in patients with mixed cryoglobulinemia ${ }^{21}$.

Table 2 shows the immunochemical composition of many cryoglobulins that have been studied. Such structural heterogeneity is the basis for the classification proposed by BROUET et al. ${ }^{14}$ and accepted by most investigators. In this classification three types of cryoglobulin are reported:

1. Cryoglobulins of the first type are made up of a single monoclonal Ig, may be found almost exclusively in patients with multiple myeloma or Walden. ström's macroglobulinemia, and account for lower than $20 \%$ of cryoglobuline. mias. Most often the monoclonal Ig is IgM, less often IgG usually belonging to $\gamma_{2}$ or $\gamma_{3}$ heavy chains, less frequently $\gamma_{1}$. Only one case of IgG4 cryoglobulinemia has been reported ${ }^{64}$. In rare cases the cryoglobulins of the first type are made up of $\operatorname{lgA}^{68}$, perhaps with the properties of pyroglobulins as well ${ }^{85}$, or of light chains that can reach high serum levels once renal insufficiency has developed ${ }^{2,14,47}$. Occasionally single IgG cryoglobulins have been shown to consist of IgG-IgG immune complexes ${ }^{21}$.

2. Cryoglobulins of the second type are mixed, usually $\operatorname{IgM} \cdot \operatorname{IgG}$, and one of the two fractions is monoclonal (tab. 2). These have an incidence of approximately $40 \%$. As a rule, neither of the two components is able to precipitate in the cold individually, but it is the IgM fraction that behaves as an incomplete cryoglobulin, in that when this is reacted with an IgG from another subject, cryoprecipitation does occur. Vice versa, if the $\operatorname{IgG}$ component of the cryoglobulin is reacted with homologous IgM, cryoprecipitation is no longer detectable ${ }^{49}$.

The most frequent form in this group is the so-called "essential mixed cryoglobulinemia' (EMC), characterized by the occurrence in the serum of IgM-IgG complexes. While the IgG is always polyclonal, the IgM is monoclonal, usually possesses kappa light chains and is endowed with rheumatoid factor activity. In addition to classical rheumatoid factor activity, anti-idiotypic activity has been demonstrated in a significant number of the IgM fractions from these mixed cryoglobulins ${ }^{31}$. These cryoglobulins are often associated with vasculitis, skin reactions and glomerulonephritis ${ }^{55}$. Metabolic studies of the constituent fractions from patients with cryoglobulinemia have shown no significant differ- 
1) lymphoproliferative diseases

- multiple myeloma ${ }^{74}$

- Waldenström's macroglobulinemia ${ }^{12}$

- chronic lymphatic leukemia and lymphoma ${ }^{14}$

- angioimmunoblastic lymphadenopathy ${ }^{32}$

2) autoimmune and immune complex diseases

- systemic lupus erythematosus ${ }^{16}$

- rheumatoid arthritis ${ }^{86}$

- Sjögren's syndrome ${ }^{91}$

- Felty's syndrome ${ }^{86}$

- scleroderma ${ }^{39}$

- polyarteritis nodusa (HBsAg.positive and -negative) ${ }^{73}$

- Behçet's syndrome ${ }^{71}$

- Schönlein-Henoch purpura ${ }^{30}$

- autoimmune vasculitis ${ }^{17}$

- glomerulonephritis ${ }^{53}$

- autoimmune thyroiditis 56

- polymyositis 27

- sarcoidosis $^{79}$

- celiac disease ${ }^{23}$

- pemphigus vulgaris 59

3) infectious diseases

A) viral

- acute hepatitis ${ }^{75}$

- chronic hepatitis B virus infection ${ }^{54}$

- infectious mononucleosis ${ }^{82}$

- cytomegalovirus infections ${ }^{32}$

B) bacterial

- lepromatous leprosy"

- subacute bacterial endocarditis ${ }^{38}$

- acute poststreptococcal glomerulonephritis ${ }^{53}$

- syphilis ${ }^{43}$

- venereal lymphogranuloma ${ }^{\text {H }}$

C) parasitic

- echinococcosis ${ }^{10}$

- malaria!

- toxoplasmosis 81

- leishmaniasis ${ }^{62}$

D) fungal

- coccidioidomycosis $^{29}$

4) liver diseases

- biliary cirrhosis ${ }^{83}$

- Morgagni-Laennec's cirrhosis ${ }^{19}$

- alcoholic cirrhosis ${ }^{34}$

Tab. 1 - A tentative list of diseases which may be associated with cryoglobulinemia. 


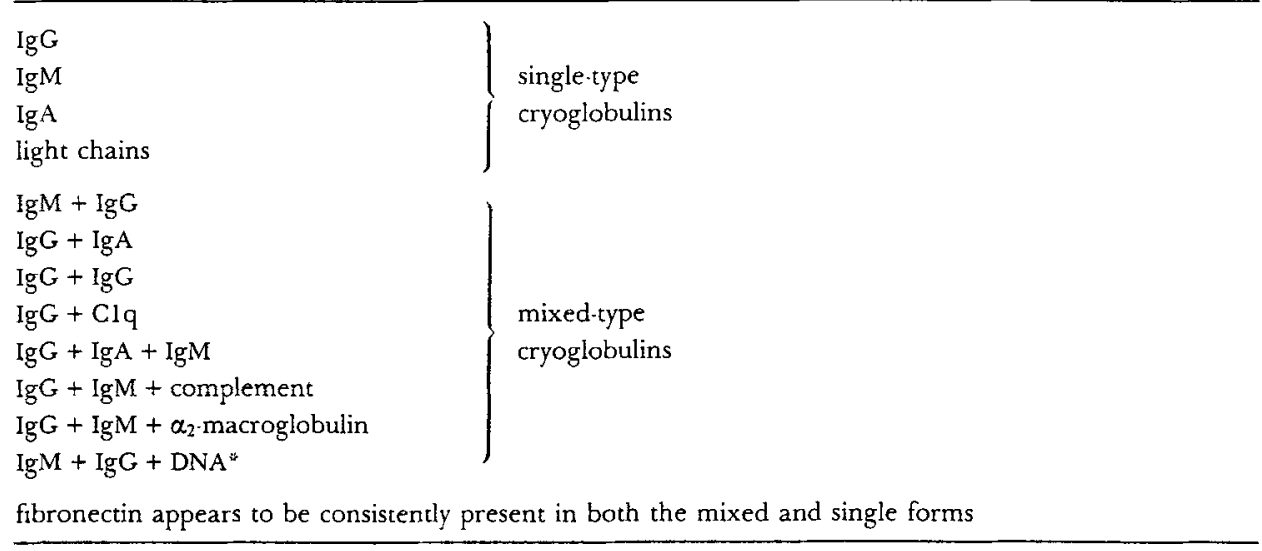

* Nucleic acids may be found in other forms of mixed cryoglobulins.

Tab. 2 - Immunochemical composition of the cryoglobulins.

ences between the metabolism of IgG purified from the complex and normal $\operatorname{IgG}{ }^{72}$.

Other mixed cryoglobulins of the second type are made up of IgA-IgG, with $\operatorname{Ig} A$ usually being the monoclonal component ${ }^{61}$, or else IgG-IgG in which one IgG is monoclonal with rheumatoid factor activity and the other is poly. clonal ${ }^{14}$.

3. Cryoglobulins of the third type include the mixed polyclonal cryoglobulins which appear to be fairly common, with an incidence higher than $40 \%$. In this group, in addition to some of the 'essential' cases apparently unassociated with concomitant diseases, the forms that accompany infectious and/or inflamma. tory diseases are usually found.

Under the nosological point of view, single-type monoclonal cryoglobulinemia (type I) and mixed cryoglobulinemia with one monoclonal component (type II) should be considered lymphoproliferative diseases. Indeed, in the first group clinical diagnoses have mostly been either Waldenström's macroglobulinemia or multiple myeloma. The large majority of patients with type II cryoglobulins either have EMC or Waldenström's macroglobulinemia, in which the monoclonal component (IgM) has rheumatoid factor (anti-immunoglobulin) activity, thus accounting for the presence of circulating IgM-IgG immune complexes. Even cases with IgA-IgG and IgG-IgG cryoglobulins should possibly be considered lymphoproliferative diseases, with monoclonal IgA or IgG components able to react with polyclonal IgG.

The nosological classification of mixed polyclonal cryoglobulinemias (type III) is somewhat more complex. While some forms (those secondary to acute or chronic infectious diseases) might be considered to be specific antibody responses (often transitory and not necessarily abnormal) to some antigenic stimuli such as streptococcal antigens ${ }^{36}$ or hepatitis B virus (HBV) ${ }^{46}$, type III EMC should be considered a lymphoproliferative disease because of the peculiar clinical picture, with its characteristic clinical development into progressive damage of various organs. 


\section{PATHOGENESIS}

The mechanisms by which cryoglobulins originate are still largely un known. Some investigators ${ }^{6,21}$ have suggested that, in response to persistent antigenic stimulation by antigens of various types, the immune system produces a secondary antibody response, most often IgG that, after reaction with the antigen, becomes autoantigenic itself. The next response to this is the production of IgM, which causes formation of immune complexes (primary antigenIgG-IgM) that precipitate in the cold for not yet understood reasons. BALLARD et al. studied a cryoprecipitable monoclonal IgM with high affinity for the antigen, obtained by stimulating the splenocytes of already immunized mice with fluorescein isothiocyanate, and concluded that cryoglobulins are the expression of a hyperimmune response. In fact, the process of maturation of the immune response in terms of the affinity of the binding to Ag might cause somatic mutations of the Ig-secreting cells, causing them to produce an Ig with elevated affinity and with cryoglobulin properties.

Some patients with systemic lupus erythematosus were found to have mixed IgG-IgM cryoglobulins containing DNA, which could not be studied further because it was present in only very small amounts ${ }^{6}$. In more than a few patients with mixed cryoglobulinemia it has been possible to identify denatured DNA in the cryoprecipitated immune complexes, intimately associated with the complex itself ${ }^{8}$. In fact, this DNA can be attacked by DNAse only at pH 3, whereas the enzyme is not active at neutral $\mathrm{pH}$. This is unlike the situation for the DNA bound to normal immunoglobulins, which is accessible to DNAse at all $\mathrm{pH}$ values ${ }^{6}$. Possibly the DNA so closely associated with the IgG-IgM complex and inaccessible to DNAse at $\mathrm{pH} 7$ becomes accessible at strongly acid $\mathrm{pH}$ because of the dissociation of the IgG-IgM components known to occur at acid $\mathrm{pH}$. The DNA might come either from increased destruction of host cells or from viral particles in the form of single-stranded DNA and might, in at least some cases, be the antigen that initiates the immunological reaction responsible for cryoprecipitation ${ }^{6,21}$.

In 1977 LEVo et al. ${ }^{46}$ reported a significantly high correlation between EMC and chronic infection with hepatitis B virus. HBsAg or anti-HBs were found in $52 \%$ of the sera from patients with EMC, while positive responses for at least one of the markers for $\mathrm{HBV}$ infection were found in $74 \%$. In addition, electron microscopy revealed that some cryoprecipitates contained spherical or tubular particles of 20 and $27 \mathrm{~nm}$ referable to $\mathrm{HBV}$ and also contained Dane particles. The association of EMC with exposure to HBV was thought to be so strong that some investigators proposed calling it mixed cryoglobulinemia secondary to hepatitis $\mathrm{B}$ virus instead of $\mathrm{EMC}^{48}$. This opens up a possibility of explaining another frequently found association, that of cryoglobulinemia and chronic liver disease. In these cases, $\mathrm{HBV}$ might on one hand be the etiological agent for the chronic liver disease, and on the other it might be the antigen responsible for immunologic stimulation that brings about formation of the IgM-IgG-HBV immune complexes which may have cryoprecipitating properties.

Additional evidence in favor of the etiological responsibility of $\mathrm{HBV}$ for EMC was obtained by DRÜEKE et al. ${ }^{24}$, who studied patients on hemodialysis. Three of 266 carriers of HBsAg developed EMC, with HBsAg and anti-HBs in 
the cryoprecipitate, followed by necrotizing vasculitis, while none of the pa. tients without HBsAg developed either cryoglobulinemia or vasculitis.

More recently, a few studies ${ }^{67.75}$ have somewhat reshaped the importance of the association of EMC and HBV, suggesting that there is not such a large presence of at least one of the markers of $\mathrm{HBV}$ in the cryoprecipitates ${ }^{28}$. In addition, even in those cases that do have HBV markers, it was possible that the chronic HBV infection became established in subjects who, by already having cryoglobulinemia, should possibly be considered more prone to infection by $\mathrm{HBV}$ in view of their immunological abnormalities. What is more, the cryoprecipitating property should not be considered specific for the IgM-IgG. HBV immune complexes, since cryoglobulins are found with even greater frequency than $\mathrm{HBV}$ in subjects with many infectious and parasitic diseases.

Mixed cryoglobulinemia was produced in the rabbit by repeated inoculations with streptococcal vaccine or with live streptococci $\mathrm{B}^{36}$. In this infectious disease, in which the pathogenic agent disappears once it has been cured, cryoglobulinemia is transient and cannot be demonstrated within a few weeks or months after recovery. Therefore, formation of cryoglobulins during antibody response to whatever antigen should be considered neither exceptional (since it occurs in different diseases) nor abnormal. What is abnormal in the cryoglobulinemic syndrome, therefore, is the accumulation of cryoglobulins in the blood, which does not probably result from hyperproduction only, but also from reduced catabolism by the macrophages.

\section{MECHANISMS OF THE CRYOPRECIPITATION}

Very little is known about the molecular basis for the different solubility in the cold of the cryoglobulins as compared with other immunoglobulins. The most likely explanation is that cryoprecipitation is a simple solubility phenom. enon based on an unfavourable interaction between cryoglobulins and the solvent at low temperatures ${ }^{\text {s. }}$. The solubility of proteins depends on various factors, namely concentration, temperature, $\mathrm{pH}$, ionic strength of the solution, as well as surface charge (which depends on the amino acid residues and the carbohydrate content).

A series of data from MELTZER and FRANKLIN ${ }^{55}$ indicates that $90 \%$ of the total quantity of monoclonal IgG or IgM cryoglobulins in a serum is precipitated at $0^{\circ} \mathrm{C}$ in $0.15 \mathrm{M} \mathrm{NaCl}$ solution when the cryoglobulin concentration is 0.5 to $4 \mathrm{mg} / \mathrm{ml}$ and the $\mathrm{pH}$ is between 4.5 and 8.5 .

Several investigators have reported changes in the primary structure of the heavy and light chains of the cryoglobulin that they consider to be responsible, at least in part, for the different solubility of the cryoglobulins. Cummincs ${ }^{18}$ found low percentages of tyrosine and tryptophan in a monoclonal IgG cryo. globulin and UKI et al. ${ }^{80}$ and MIDDAUGH et al. ${ }^{58}$ found a deficiency of tyrosine in the heavy chains of two different monoclonal IgM cryoglobulins. UKI et al. ${ }^{80}$ also detected in many cryoglobulins low basic amino acid (lysine and arginine) and aromatic amino acid (phenylalanine and tyrosine) contents associated with increased glutamic acid. On the other hand, WANG et al. ${ }^{84}$ reported that the light chains of IgG and $\operatorname{IgM}$ cryoglobulins had low serine content.

Under normal conditions, the polar amino acid residues (aspartic acid, glutam. ic acid, arginine, histidine, lysine, serine, tyrosine, threonine) are on the surface 
of the molecule and provide most of the charge and solubility of the mole. cule itself, whereas the non-polar residues are located in the hydrophobic inside of the molecule. Decreases in the polar residues will, therefore, decrease the negative charge and the solubility of the protein, but within certain limits this can be overcome by the formation of dimers or trimers, which increases the negative charge on the surface in proportion to the mass, so that the same number of negative charges is distributed over a smaller total surface as compared with that of the individual monomers ${ }^{3}$. This preserves the solubility of the aggregates of cryo- or pyroglobulins under suitable thermal conditions. However, decreasing the temperature causes further changes in the steric conformation of the entire molecule, thus exposing non-polar residues with further loss of solubility and the formation of cryoprecipitate. Reheating to $37^{\circ} \mathrm{C}$ reestablishes the initial steric conformation of the molecule ${ }^{i 9}$.

The $p H$ of the solution is also important for the solubility of proteins, affecting the secondary and tertiary structures of the molecule. At $\mathrm{pH}$ below 5 or above 8 , for example, the loss of negative surface charges becomes less critical, so that cooling does not cause precipitation ${ }^{56}$. There are, however, exceptions such as one particular monoclonal IgM described by MidDaugh et al. ${ }^{58}$ that precipitated at $0{ }^{\circ} \mathrm{C}$ even in solutions at $\mathrm{pH} 10$.

In addition, steric changes in the molecule that follow its binding to antigen are very important for function, since they expose the binding site to comple. ment and can also decrease the surface charge and thus the solubility at low temperatures.

Even though the carbohydrate content of many cryoimmunoglobulins is with in normal limits, some investigators have shown it to be reduced or absent in a few instances. SAHA et al. ${ }^{69}$ described an IgG cryoimmunoglobulin with a low glycosamine content. ZinNemAN et al. ${ }^{92}$ found no sialic acid in the IgG component of a mixed IgG-IgM cryoglobulin and made an artificial mixed cryoglobulin by combining an anti.IgG IgM with a normal IgG that had been desialylated by incubation with neuraminidase.

Even uncharged carbohydrates (fucose, hexose, hexosamine) contribute indirectly to the solubility of the molecule ${ }^{3}$. When these carbohydrates are removed with glycosidase, a decreased solubility occurs up to $37^{\circ} \mathrm{C}$. One patient with Sjögren's syndrome had a monoclonal IgG cryoglobulin with low fucose and hexose content that after precipitation had to be reheated to $52^{\circ} \mathrm{C}$ before it dissolved ${ }^{91}$. Attempts to localize the segments of the molecule that were responsible for cryoprecipitation by enzymatic fragmentation of the cryoglobulin gave unclear results, but the various fragments obtained [Fab, $\mathrm{F}\left(\mathrm{ab} \mathrm{b}^{\prime}\right), \mathrm{Fc}$, monomeric subunits of $\left.\mathrm{IgM}\right]$ no longer cryoprecipitated ${ }^{\text {s8 }}$.

Fibronectin has recently been shown to play an important role in cryoprec ipitation. It is a protein with molecular weight 450,000 daltons, consistently appears to be a component of mixed cryoglobulins (plate $1 \mathrm{E}$ ), especially those from patients with autoimmune diseases, and seems possibly responsible for the formation of the cryoprecipitate ${ }^{7,19,89}$. Fibronectin has also been found in the precipitates of single-type monoclonal cryoglobulins ${ }^{20}$, in which it accounts for $10-14 \%$ of the total protein ${ }^{17}$. Its role in the formation of the cryoprecipitate is emphasized by the fact that, when fibronectin is removed from the plasma chromatographically, there is a notable decrease in the ability of the cryoglobulins to precipitate in the cold. The capacity to cryoprecipitate is regained by 
the addition of fibronectin. However, the possible interactions of fibronectin and cryoglobulin during cold precipitation are still poorly understood. The consistent presence of fibronectin in the cryoprecipitate might be due either to contamination or to the binding of fibronectin to some component (not necessarily an immunoglobulin) of the cryoglobulin. This latter appears to some extent supported by the following observations: 1) fibronectin has been found in association with all the polyclonal cryoglobulins studied; 2) repeated solubili. zation and reprecipitation of cryoglobulins do not result in any loss of fibronec. tin, as it does of other contaminating plasma components such as albumin; 3) the electrophoretic mobility of fibronectin is significantly changed when the cryoprecipitate is immunoelectrophoresed directly without having been solubilized ${ }^{89}$. Since the only cryoglobulin components that are essential for formation of cryoprecipitate are the immunoglobulins, it would seem that they are indeed the effective substrate for fibronectin attachment. Finally, the change in electrophoretic mobility of the Ig and of fibronectin might be due to their interactions.

It is possible that some Ag-Ab complexes that are able to bind fibronectin are soluble at physiological temperatures but, when they are combined with fibronectin at low temperature, they form a precipitate ${ }^{89}$. Another possibility is that fibronectin can be bound to the collagen-like portions of Clq that are present in many cryoglobulins, especially those in patients with connective tissue diseases ${ }^{87}$. Finally, it seems also possible that a number of large normal serum proteins, including fibronectin, may be endowed with cryoprecipitability. In the course of inflammatory situations such proteins would indeed behave as acute-phase reactants and increase to a threshold beyond which intermolec. ular attractive forces become prevalent. The molecular aggregation between these non-Ig proteins and immune complexes would be enhanced at low temperatures, thus resulting in the cryoprecipitation of otherwise cold-soluble immune complexes ${ }^{35}$.

\section{STRUCTURAL STUDIES}

Several investigators have studied the ultrastructure of a number of cryoprecipitates. Single monoclonal $\operatorname{lgG}$ cryoglobulins precipitate in cylindrical tubules, the transverse sections of which have a ring appearance, sometimes with electron-dense bridges between them, while longitudinal sections look like the rungs of a ladder. The walls of the tubules probably consist of protein subunits made up of the Fab components, while the FC components project outside the cylinder ${ }^{76}$. The precipitate consisting of mixed IgG-IgM cryoglobulins looks under the electron microscope like a structure with a central tubule surrounded by material in the form of the spokes of a wheel. The subunits that form the walls of the central tubule look in longitudinal section like the rungs of a ladder ${ }^{76}$. The material arrayed around the tubule might be IgM bound to the Fc component of the IgG that probably makes up the wall of the tubule.

\section{LABORATORY DATA}

Blood samples drawn from patients with cryoglobulinemia into a syringe are warmed to $37^{\circ} \mathrm{C}$ and set to coagulate in a $37^{\circ} \mathrm{C}$ water bath or oven. The serum (which may be turbid) is stored in a refrigerator at +2 to $4{ }^{\circ} \mathrm{C}$ for a 
few days. The cryoglobulin precipitates in the bottom of the tube (plate 1B) and can be easily washed with cold buffered saline solution to remove the other serum components, including normal Ig. Cryoglobulins are then ready for immunological typing by immunoelectrophoresis. If the whole serum is centrifuged at $1,400 \mathrm{rpm}$ and at $4{ }^{\circ} \mathrm{C}$ in a Wintrobe tube, one can obtain the percent of cryoprecipitate in total serum, which is called the cryocrit. After electrophoresis there is often a homogeneous band, usually in $\gamma$ position, and occasionally in $\beta$ position. The immunoelectrophoretic pattern is often characteristic (plate $1 \mathrm{C}$ ). There may be either polyclonal hypergammaglobulinemia or hypogammaglobulinemia. The erythrocyte sedimentation rate is usually high, especially for patients with hypergammaglobulinemia. Analytical ultracentrifugation of the isolated cryoglobulins often shows typical patterns (plate 1D).

Some cryoglobulins, especially the IgM monoclonal cryoglobulins with rheumatoid factor activity that are seen in Waldenström's macroglobulinemia and the monoclonal components of mixed cryoglobulins, have antiimmunoglobulin activity. In addition, mixed cryoglobulins may have anticomplementary activity ${ }^{92}$. There have also been descriptions of decreased serum bactericidal activity and inhibition of chemotaxis, probably due to coating of the leucocytes with cryoglobulin ${ }^{92}$. In general, there are low serum complement levels, especially of $\mathrm{C} 4$ which may reach values lower than 5 $\mathrm{mg} / \mathrm{dl}^{32}$. Cell-mediated immunity and suppressor cell activity have also been found to be impaired ${ }^{5.57}$.

For largely unknown reasons $70 \%$ of the patients are anemic, their hematocrits being less than $35 \%$. There may also be a spurious leucocytosis because the electronic counters include aggregates of cryoglobulin in the counts ${ }^{25}$. In patients with mixed cryoglobulinemia, bone marrow examination reveals focal lymphocyte aggregation or a slight increase in plasma cells ${ }^{32}$, while the bone marrow appearance of patients with monoclonal cryoglobulinemia is typical of those with multiple myeloma or Waldenström's macroglobulinemia.

\section{CLINICAL MANIFESTATIONS}

Our experience is based on the study of over 180 patients with cryoglobu. linemia (tab. 3), one third of whom have been followed up for several years. Clinical diagnoses include lymphoproliferative diseases, connective tissue diseases and other autoimmune disorders, as well as chronic infectious diseases. Among patients belonging to the infectious disease category, a special mention deserve 3 patients with HTLVIII/LAV-related positive serology associated with significant amounts of circulating type III cryoglobulin, suggesting that patients with acquired immunodeficiency syndrome (AIDS), AIDS-related complex and lymphadenopathy syndrome should be carefully screened for the occurrence of cryoglobulinemia. However, no associated disease could be clearly detected in 68 out of 181 patients despite thorough clinical evaluation and prolonged follow-up. Thus, this group of patients classified as having 'essential' mixed cryoglobulinemia (EMC) is the largest one in this series (tab. 3), as well as in most large series published so far ${ }^{14,32,33.56}$.

Not all subjects with cryoglobulinemia have specific signs and symptoms ${ }^{60}$, although $80-85 \%$ of the patients with monoclonal cryoglobulinemia have clini- 


\begin{tabular}{|c|c|c|c|c|}
\hline \multirow[b]{2}{*}{ diagnoses } & \multicolumn{4}{|c|}{ cryoglobulin } \\
\hline & $\begin{array}{l}\text { type I } \\
\text { (single } \\
\text { type) }\end{array}$ & $\begin{array}{c}\text { rype } \mathrm{Il} \\
\text { (mixed, with a } \\
\text { monocknal component) }\end{array}$ & $\begin{array}{l}\text { type III } \\
\text { (mixed, } \\
\text { polyclonal) }\end{array}$ & total \\
\hline multiple myeloma & 15 & - & - & 15 \\
\hline Waldenström's macroglobulinemia & 11 & 9 & - & 20 \\
\hline $\begin{array}{l}\text { chronic lymphatic leukemia and } \\
\text { malignant lymphoma }\end{array}$ & 5 & 2 & - & 7 \\
\hline bacterial endocarditis & - & 1 & 1 & 2 \\
\hline lepromatous leprosy & - & 1 & 6 & $?$ \\
\hline $\begin{array}{l}\text { liver cirrhosis and chronic } \\
\text { active hepatitis }\end{array}$ & - & 9 & 24 & 33 \\
\hline systemic lupus erythematosus & - & 5 & 8 & 13 \\
\hline rheumatoid arthritis & - & 3 & 4 & 7 \\
\hline progressive systemic sclerosis & - & 1 & 2 & 3 \\
\hline Sjögren's syndrome & - & 2 & 2 & 4 \\
\hline periarteritis nodosa & -- & - & 1 & 1 \\
\hline idiopathic thrombocytopenic purpura & - & 1 & 1 & 2 \\
\hline $\begin{array}{l}\text { LAS (HTLVIII/LAV positive } \\
\text { lymphadenopathy syndrome) }\end{array}$ & - & - & 3 & 3 \\
\hline 'essential' mixed cryoglobulinemia & - & 37 & 31 & 68 \\
\hline total & 31 & 71 & 83 & $185^{*}$ \\
\hline$(\%)$ & (17.1) & $(39.2)$ & $(45.8)$ & \\
\hline
\end{tabular}

* A few patients had more than one diagnosis.

Tab. 3 - Clinical diagnoses in $181^{*}$ patients with cryoglobulinemia. Cumulative experience collected in the Institutes of Patologia Medica and 2nd Clinica Medica, University of Bari, up to June, 1986.

cal manifestations after exposure to cold or at other times ${ }^{33}$. In the patient population of GoREvic et al. ${ }^{32}$ more than two thirds of the patients were females, with mean age of 50.7 years, range 21 to 72 years, and without any significant racial disproportions. In addition, cryoglobulinemia has been repeatedly reported to affect several members of the same family ${ }^{22.63}$. The most frequent signs and symptoms of mixed cryoglobulinemia are listed in tabs $4 \mathrm{~A}$ and $4 \mathrm{~B}$.

Skin reactions are seen very frequently (plate $1 \mathrm{~A}$ ). Many patients are seen first by dermatologists, to whom they go because of purpura, leg ulcers, Raynaud's phenomenon, edema and urticaria. The purpura usually does not cause itching, appears intermittently on exposed parts of the body, especially the legs, fingers, ears, nose ${ }^{13}$. It occurs most frequently in the winter, lasts for 3.10 days for each poussée (sometimes the poussées follow each other with striking frequency), and eventually leaves an area that is hardened and diffusely hyperpigmented. Biopsies of the cutaneous purpuric lesions show vasculitis, with endothelial swelling, extravasation of blood, perivascular infiltration with mononuclear and polymorphonuclear cells and damage to the subcutaneous interstitium. Immunofluorescence studies show $\operatorname{IgM}, \operatorname{IgG}$ and/or C4 in the vessel walls of the lesioned skin.

Chronic ulcers of the legs are especially frequent in the supramalleolar regions, are always associated with purpura and are probably due to vasculitis. 


\begin{tabular}{|c|c|}
\hline signs and symptoms & $\begin{array}{l}\text { approximate } \\
\text { percentages }\end{array}$ \\
\hline purpura & 90 \\
\hline heparomegaly & 70 \\
\hline splenomegaly & 50 \\
\hline arthralgia & 60 \\
\hline weakness & 60 \\
\hline arterial hypertension & 35 \\
\hline Raynaud's phenomenon & 40 \\
\hline leg ulcers & 30 \\
\hline cold urticaria & $\%$ \\
\hline papules, pustules & $*$ \\
\hline gangrene of the fingers/toes & $*$ \\
\hline edema of the legs, anasarca & $\because$ \\
\hline symmetrical/asymmetrical polyneuropathy & $\because$ \\
\hline mental confusion, coma & $\Leftrightarrow$ \\
\hline cerebrovascular accidents & $\because$ \\
\hline intestinal vasculitis with abdominal pain & $\because$ \\
\hline Sjögren's syndrome & $\%$ \\
\hline hyperviscosity syndrome & $\because$ \\
\hline congestive heart failure & $*$ \\
\hline pericarditis, cardiac infarction & $*$ \\
\hline pleural effusion, pulmonary fibrosis & $*$ \\
\hline hemoptysis & $\because$ \\
\hline
\end{tabular}

*Usually lower than $30 \%$.

Tab. $4 \mathrm{~A}$. Clinical signs and symptoms frequently observed in patients with mixed cryoglobulinemia.

\begin{tabular}{lc}
\hline finding & $\begin{array}{c}\text { approximate } \\
\text { percentages }\end{array}$ \\
\hline mild to heavy proteinuria & 50 \\
renal failure & 40 \\
glomerulonephritis (renal biopsy) & 35 \\
abnormal liver function tests & 30 \\
active chronic hepatitis (liver biopsy) & 30 \\
fever of unknown origin & 20 \\
recurrent bacterial infections & 20 \\
thyroiditis & $*$ \\
renal tubular acidosis & $*$ \\
papillary necrosis & $*$ \\
demyelinization & $*$ \\
occlusion of the central retinal artery & $*$ \\
uveitis & $*$ itis media
\end{tabular}

"Usually lower than $20 \%$.

Tab. 4B - Other findings in patients with mixed cryoglobulinemia. 

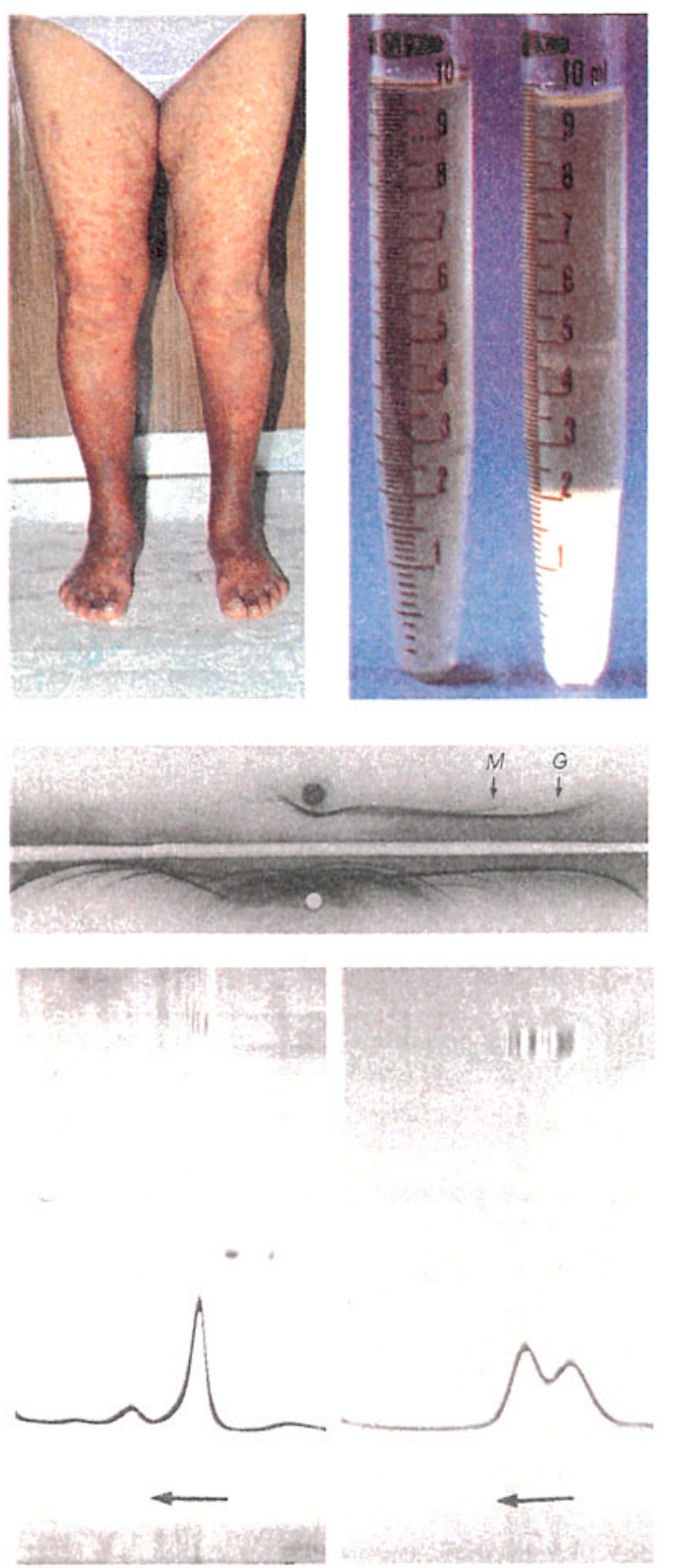

D) Analytical ultracentrifugation (speed: 59,780 rem; temperature: $20^{\circ} \mathrm{C}$ ) of the isolated cryoglobulins from two patients affected with type I and type III cryoglobulinemia, respectively. Arrows indicate the direction of sedimentation. At $\mathrm{pH} 7.0$ a single 195 peak is visible in the ultracentrifugal pattern on the left, along with much smaller amounts of proteins sedimenting faster and slow. er than the prominent 195 peak. The pattern on the right shows two main components, incompletely dissociated at this $\mathrm{pH}$, with sedimentation coefficients of approximately $7 \mathrm{~S}$ and $19 \mathrm{~S}$.
A) Chronic purpuric eruptions affecting legs and thighs of a patient with a 7 -years' history of essential mixed cryoglobuline. mia (EMC). Note the diffusely hyperpig. mented dyschromias on the legs.

B) As compared with a pooled normal human serum (left), the serum in the right tube shows a whitish cryoprecipitate which accounts for approximately $20 \%$ of the total proteins. Tubes were kept for $72 \mathrm{~h}$ at $4^{\circ} \mathrm{C}$ and then centrifuged at $1,400 \mathrm{rpm}$ for $10 \mathrm{~min}$.

C) Immunoelectrophoresis of the purified cryoglobulin (upper pattern), isolated from the serum shown in the right tube of $B$ ) and, by comparison, of a pooled normal human serum (lower pattern). The trough was filled with a horse anti-human serum. The two lines recognizable in the cryoglobulin pattern can be identified as IgG and IgM by specific antisera and are fused for most of their length suggesting the im. mune complex nature of the cryoprecipi. tate. Owing to its poor solubility, a certain amount of protein remains in the upper well without migrating into the agar gel.

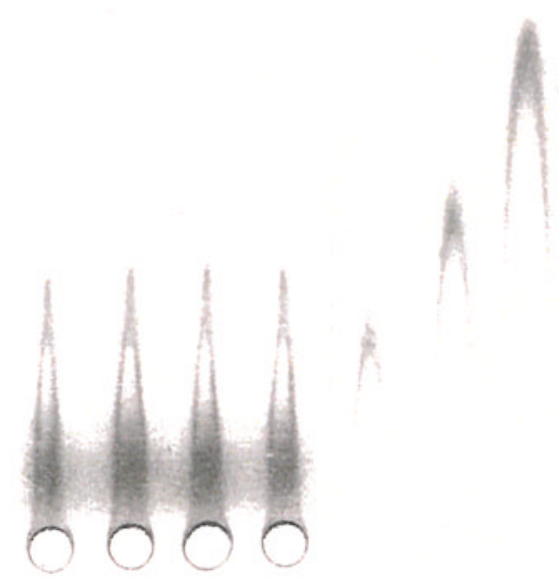

E) 'Rocket' (Laurell's) electroimmunoassay in $1 \%$ agarose gel containing a rabbit antiserum to human fibronectin (FN). Four dif. ferent purified cryoglobulins $(3 \mathrm{mg} / \mathrm{ml}$ ) are placed in wells 1.4 , whereas wells 5.7 are filled with standard FN solutions (500, 750 and $1,000 \mu \mathrm{g} / \mathrm{ml}$, respectively). In spite of poor solubility and incomplete migration, a rocket is clearly visible for each cryoglobulin sample, indicating that appreciable amounts of FN are present in all the cryoproteins tested. 
F. DAMMACCO et al.

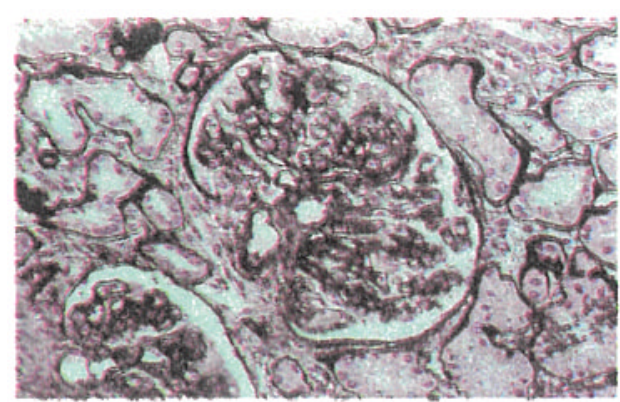

F) Renal biopsy (silver methenamine stain, $x$ 40) from a patient with EMC. A representative glomerulus showing mesangiocapillary glomerulopathy with proliferacion of mesangial cells and accentuated lobulation.

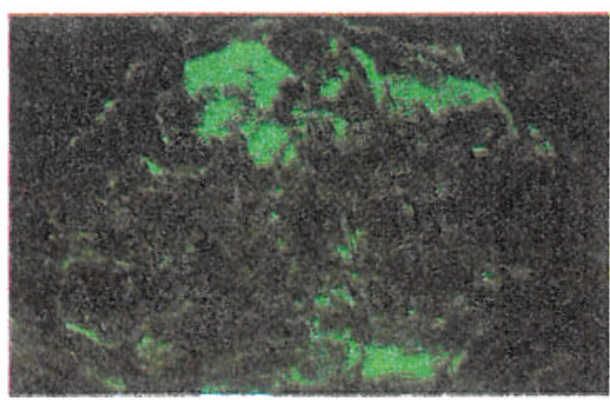

H) Immunofluorescence on a renal biopsy specimen (fluorescein isothiocyanate conjugated antihuman IgM stain, $x$ 250) showing subendothelial and intraluminal glomerular deposits of $\mathrm{IgM}$. Focal 'hyaline thrombi' appear intensely fluores. cent. Similar patterns were obtained in sections stained for $\operatorname{IgG}, \mathrm{C} 3$ and kappa light chains.

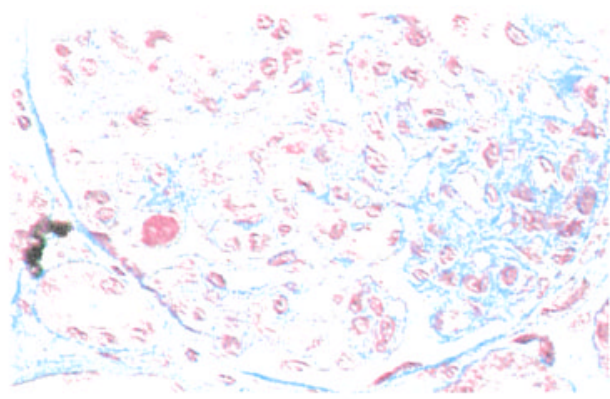

G) Renal biopsy from the same patient (acid fuchsin orange $G$ stain, x 160). An occlusive thrombus can be seen in a capillary lumen.

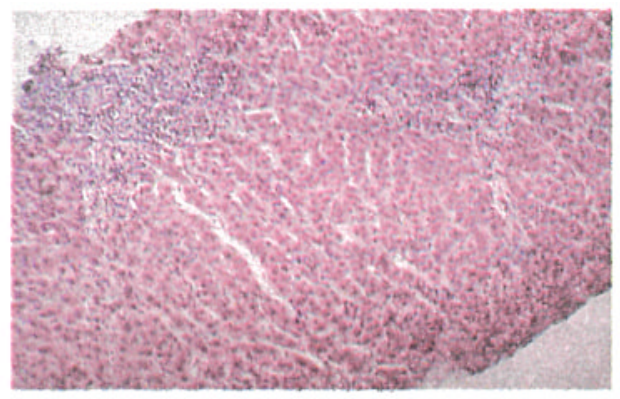

I) Liver biopsy from a patient with EMC (hema toxylin and eosin stain, $\mathrm{x}$ 71). Dense infiltration of portal tracts with chronic inflammatory cells, somewhat extending into the surrounding periportal parenchyma, resulting in piece meal necrosis.
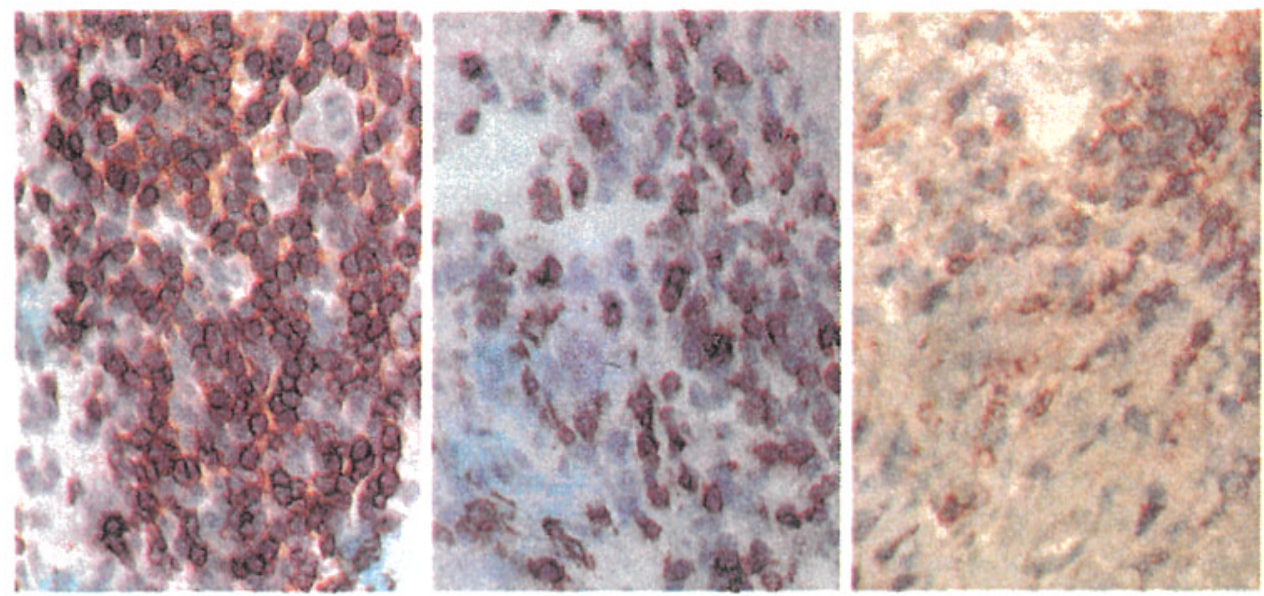

L-N) Immunohistochemical staining (avidin-biocin-peroxidase, x 160) of $\mathrm{T} 3+$ lymphocytes (L) and of the $\mathrm{T} 4+$ helper-inducer (M) and the $\mathrm{T} 8+$ suppressor-cytotoxic (N) subpopulations. Heavy lymphocyte infiltration in the portal and periportal areas: phenotypic characterization shows I8t cells to be largely prevalent. 
When they appear in the absence of severe stasis dermatitis, one should suspect cryoglobulinemia. Erythema bullosum has been reported by KRIVO and MILLER ${ }^{+2}$.

Sometimes the first manifestation of the disease is Raynaud's phenomenon, which is present at the time of diagnosis in one-fourth of the cases ${ }^{32}$. It affects the distal parts of the limbs, the ears, the nose. There may or may not be gangrene. It occurs most frequently in patients with types I and II cryoglobulinemia.

More than $70 \%$ of the patients have arthralgia, intermittent, symmetrical and non-migrating ${ }^{32}$. It especially affects the joints of the hands and the knees (45\%), but can also affect the hips and the elbows (25\%).

Although skin manifestations and arthralgia are the most frequent in these patients, many other signs and symptoms develop during the course of the disease because of damage to other organs and systems ${ }^{90}$. The various organs may be affected at the same time as the skin or even earlier. Renal damage is characterized by diastolic hypertension; edema; proteinuria sometimes quite severe (up to $17 \mathrm{~g} / 24 \mathrm{~h}$ ), usually associated with hematuria; and impairment of renal function that may even be as bad as renal failure. Sometimes it is the symptoms of renal damage that bring the patient to the attention of the physician, but usually they follow the appearance of the purpura after a mean interval of 4 years $^{32}$. The histology of the kidney often shows necrosis of the tunica media of the renal arterioles and glomerular hypercellularity with polymorphonuclear lymphocyte infiltration (plate 1F, G). With immunofluorescence one often sees granular deposits of $\operatorname{IgG}$, IgM (plate $1 \mathrm{~N}$ ) and complement along the glomerular basal membrane and the blood vessel walls. The tubules are dilated and separated by an edematous or slightly inflamed interstitium. The histological diag. nosis is most often proliferative or membranoproliferative glomerulonephritis, which may be observed in more than one third of the patients and shows a progression to renal insufficiency in about half of them ${ }^{+1}$. Biopsies taken from patients without renal impairment show no abnormalities, suggesting that one cannot use this to predict whether or not an asymptomatic patient will develop renal damage ${ }^{32}$.

The organs in the abdomen are often involved. Physical examination shows hepatomegaly to occur in $70 \%$ of the patients and splenomegaly in about $50 \%$, accompanied by high serum alkaline phosphatase levels. There are very few, if any, subjective symptoms due to enlargement of these organs ${ }^{32}$. As already em. phasized, HBV-associated serology is not uncommon in patients with EMC and approximately $70 \%$ of these patients have evidence of hepatic dysfunction, although commonly at the subclinical level. Liver biopsy often shows a picture compatible with chronic active hepatitis (plate $1 \mathrm{r}$ ), namely infiltration of mononuclear cells in the widened portal tract, also involving the limiting plate. An increased number of total T3+ lymphocytes can be detected by immunohis. tochemical methods, such cells being mainly accounted for by T8+ suppressor / cytotoxic lymphocytes (plate 1L-N).

A delayed manifestation of the disease may be abdominal pain, sometimes se. vere, in $20 \%$ of the patients, considered to be a manifestation of intestinal vascu. litis.

The increased viscosity of the plasma may be the cause of the hyperviscosity syndrome, which is seen as retinal 'box-car' vessels, amaurosis, sensory and motor peripheral neuropathy ${ }^{26}$, central nervous system compromise with transi- 
tory hemiplegia and dysarthria, mental confusion to coma, pulmonary stasis with cyanosis, oligo-anuria. There is often congestive cardiac failure, probably due for the most part to the expansion of plasma volume because of the cryoglobulinemia.

Although pulmonary symptoms are usually absent or moderate in clinical terms, tests indicative of small airways disease may be markedly altered and roentgenographic signs of interstitial lung involvement are present in a significant number of patients?

Finally, there may be complicating infections (pulmonary tuberculosis, herpes zoster, bacterial pneumonia, etc.).

\section{PYROGLOBULINS}

Pyroglobulins are immunoglobulins that form a gel when the serum is heated to $56.60{ }^{\circ} \mathrm{C}$ for $30 \mathrm{~min}^{\text {i0 }}$. This precipitate is irreversible and does not respond to changes in temperature, $\mathrm{pH}$ or concentration, unlike the precipitates or gels formed by cryoglobulins or Bence Jones protein.

The phenomenon was discovered by chance toward the end of the last century during a complement fixation test for the diagnosis of syphilis, when the serum was inactivated by heating at $56^{\circ} \mathrm{C}$. It was interpreted at that time as being due to the presence of Bence Jones protein in the serum. Only in 1953 did MARTIN and MATHIESON ${ }^{\text {in }}$ recognize that these proteins were not the same as the Bence Jones protein because their precipitate was irreversible. They named them pyroglobulins. Their existence was confirmed by Huisman et al. ${ }^{37}$ in 1956, who analyzed their amino acid composition.

In most cases pyroglobulins are associated with multiple myeloma and macroglobulinemia or with lymphoproliferative diseases ${ }^{t 0}$. There have also been a few cases with metastatic carcinoma or systemic lupus erythematosus ${ }^{51}$.

Pyroglobulins were found in $8(2 \%)$ of 260 patients with monoclonal gammapathies studied by INVERNizzi et al. ${ }^{\text {th}}$, more frequently in patients with Waldenström's macroglobulinemia, especially if they also had cryoglobulinemia, than in patients with myeloma.

That M-components behaved as pyroglobulins was shown electrophoretically by the loss of the M-component in the serum after precipitation of the py. roglobulin. To date only single monoclonal pyroglobulins have been found. Many pyroglobulins are monoclonal IgG components; others are monoclonal $\operatorname{IgM}$ and are found in patients with Waldenströn's macroglobulinemia or lym. phoma. MCCANn et al. ${ }^{\text {i2 }}$ found IgM macroglobulinemia in a 65-year-old patient with erythrocytosis and hyperviscosity. In the literature very few reports of monoclonal IgA pyroglobulinemia can be found, usually in patients with multi. ple myeloma ${ }^{40,78}$.

One possible explanation for the strict association of pyroglobulins with paraproteins is that pyroglobulins are normally present in the serum in very low amounts and increase to high concentrations when the clone that controls their synthesis is involved in an immunoproliferative process. An alternative to this is that pyroglobulins are abnormal immunoglobulins and are not to be found in normal serum.

Pyroglobulins do not by themselves cause clinical symptoms since they do not form the pyroprecipitate until the temperature is $55.56^{\circ} \mathrm{C}$, which is never 
reached in a living human body. However, it is possible that applying heat to the skin of an individual with pyroglobulinemia could cause precipitation and obstruction of the cutaneous and subcutaneous vessels, with consequent necrosis of the skin. When they are present in high concentrations, they may cause hyperviscosity or coagulation disorders, such as increased thrombin time due to interference with fibrin polymerization, and abnormalities of platelet aggregation in response to ristocetin ${ }^{52}$.

Investigations on the formation mechanisms of the pyrogel have not provided clear results. Some investigators have found a loss of thermoprecipitability of IgM pyroglobulins when they are splitted into $7 \mathrm{~S}$ monomers ${ }^{65}$. Others have obtained pyroprecipitation with the monomers alone, but not with separated $\mathrm{H}$ or $\mathrm{L}$ chains ${ }^{15.52}$.

Studies of the carbohydrate content, a decrease in which certainly affects the cryoglobulin solubility, have not shown quantitative or qualitative variations in the pyroglobulins ${ }^{52}$. However, amino acid sequence analysis of these peculiar proteins has shown the $L$ chain to be normal, but the heavy chain to contain fewer cysteine and more glycine and leucine than normal ${ }^{52}$. This causes an imbalance between the hydrophobic non polar residues and hydrophilic polar residues on the surface of the molecule, in favor of the non-polar, and this could be the reason for abnormal secondary and tertiary structures that would make the molecule soluble at normal temperature only by formation of aggregates. When the serum is warmed to $56^{\circ} \mathrm{C}$, there would be a further change in the steric conformation of the heavy chains, with exposure of other non-polar residues inside the hydrophobic pcrtion, thus causing formation of an insoluble gel. Isolated $\mathrm{H}$ chains do not form pyrogels. Only when they are bound to $\mathrm{L}$ chains that normally change in solubility at $56^{\circ} \mathrm{C}$ do they form strong and irre. versible hydrophobic bonds.

Under the electron microscope the pyroprecipitate looks like a network of immunoglobulins strongly bonded to each other, therefore quite different from the appearance of amorphous coagulates of normal proteins precipitated at $80^{\circ} \mathrm{C}$. The hydrophobic nature of the bonding can be shown by adding an excess of sodium dodecylsulfate (SDS) to the pyrogel, in a molecular ratio of 30 to 1 . The hydrophobic component of SDS interacts preferentially with the hydrophobic bonds, breaking them, while the sulfate radical confers a negative charge on the surface of the Ig. This completely solubilizes the pyrogel as Ig-SDS complexes.

The abnormal amino acid content of the heavy chain is not the only reason for the formation of the pyrogel. A conformational change, with exposure of non-polar residues, can have the same result. In addition, even an abnormality in the light chain can possibly result in pyroprecipitation.

Pyroprecipitation is not inhibited by changing the $\mathrm{pH}$ from 3 to 9 , although it appears to be maximal at $\mathrm{pH} 7.3$, nor is it affected by changing the ionic strength of the solution. In some cases, not even reduction and alkylation of the molecule with 2-mercaptoethanol followed by addition of iodoacetamide was able to prevent the pyroprecipitation ${ }^{40}$.

\section{SUMMARY}

Cryoglobulins are serum proteins with heterogeneous etiopathogenetic and immunochemi. cal properties. What they have in common is temperature-dependent insolubility, in that at tem- 
peratures below $37^{\circ} \mathrm{C}$ (often around $4{ }^{\circ} \mathrm{C}$ ) they precipitate, and then redissolve at $37^{\circ} \mathrm{C}$. When the etiopathogenesis of the cryoglobulinemia is unknown, which is true for many patients, the condition is called idiopathic or essential cryoglobulinemia, whereas it is termed secondary whenever it appears to be associated with one of several diseases. Cryoglobulinemia has indeed been found in patients with lymphoproliferative and autoimmune disorders, liver diseases, infectious (viral, bacterial, fungal and parasitic) diseases, and so on. Cryoglobulins are usually classified according to their immunochemical properties as single-type monoclonal, mixtures of a monoclonal Ig with non-immunoglobulin material (DNA, lipoprotein, complement), mixed with one monoclonal Ig or mixed polyclonal, in which constitutive Ig fractions are polyclonal. As compared with normal Ig, cryoimmunoglobulins have sometimes been found to exhibit a peculiar amino acid structure of their heavy chains, less often of their light chains as well, and to have a lower carbohydrate content. Such structural abnormalities may contribute to their loss of solubility at low tempera. tures, possibly associated to the steric changes induced by the low temperature, causing the pre cipitate to form. The most common clinical features of cryoglobulins are correlated with vasculitis in the various organs and sometimes with increased viscosity of the plasma. Signs and symptoms include purpura, ulcers of the extremities, arthralgia, proteinuria, hepatic damage, abdominal pain, congestive heart failure, mental confusion, oligo anuria, hemorrhagic diathesis, and coma. Pyroglobulins are also serum proteins with temperature dependent insolubility. However, al. though they precipitate out of serum heated at $56^{\circ} \mathrm{C}$ for half an hour, they do not resolubilize when the serum is returned to $37^{\circ} \mathrm{C}$. Pyroglobulins have been mainly found in patients with lymphoproliferative diseases (especially Waldenström's macroglobulinemia, with or without cryoglobulinemia), systemic lupus erythematosus, and neoplasia. So far, only single monoclonal $\operatorname{IgC}, \operatorname{IgM}$ or $\operatorname{IgA}$ pyroglobulins have been described. Since they precipitate only at $56^{\circ} \mathrm{C}$, pyroglobulins do not cause clinical symptoms and they are usually discovered by chance.

\section{REFERENCES}

1. Adam C., Morel-Maroger L., Richet G.: Cryoglobulins in glomerulonephritis not related to systemic disease - Kidney int. 3, 334, 1973.

2. Alper C. A.: Cryoglobulinuria: studies of a cryo-Bence Jones protein - Acta med. scand. 179 (Suppl. 445), 200, 1966.

3. Andersen B. R., Tesar J. T., Schmid F. R., Haisty W. K., Hartz W. H. Jr.: Biological and phy. sical properties of a human $Y \mathrm{M}$-cryoglobulin and its monomer subunit - Clin. exp. Immunol. $9,795,1971$

4. Ballard D. W., Kranz D. M., Voss E.W. Jr.: Monoclonal IgM antibody exhibiting high affinity binding and cryoglobulin properties - Proc. nat. Acad. Sci. (Wash.) 80, 5071 , 1983.

5. Barbieri P., Benedettini G., Ferri C., Campa M., Bombardieri S.: Lymphocyte subpopula. tions in essential mixed cryoglobulinemia -J. Rheumatol. 13, 108, 1986.

6. Barnetr E. V., Bluestone V. R., Cracchiolo A. III, Goldberg L. S., Kantor G. L., Mcintosh R. M.: Cryoglobulinemia and disease - Ann. intern. Med. 73, 95, 1970.

7. Beaulieu A. D., Valet J.-P.. Strevey J: The influence of fibronectin on cryoprecipitate formation in rheumatoid arthritis and systenic lupus erythematosus - Arthr. and Rheum. 24, 1383, 1981.

8. Bluestone R., Goldberg L. S., Cracchiolo A., Barnett E. V.: Detection and characterization of DNA in mixed (IgM-IgG) cryoglobulins - Int. Arch. Allergy 39, 16, 1970.

9. Bombardieri S., Paoletti P., ferri C., Di Munno O., Fornai E., Giuntini C.: Lung involve ment in essential mixed cryoglobulinemia - Amer. J. Med. 66, 748, 1979.

10. Bombardieri S., Teichner A., Vicari G.: Cryoglobulinemia in echinococcosis - Proc. Soc. exp. Biol. (N.Y.) 142, 941, 1973

11. Bonomo L., Dammacco F.: Immune complex cryoglobulinemia in lepromatous leprosy. A pathogenetic approach to some clinical features of leprosy - Clin. exp. Immunol. 9, 175, 1971.

12. Bonomo L., Dammacco F., Tursi A., Trizio D.: IgM-IgG complexes in cryoglobulinemia with monoclonal or polyclonal anti-gammaglobulin IgM component. In: BONOMO L., TURK J. L. (Eds): Immune complex diseases. Proc. Int. Symposium, 1970; p. 122

13. Brody J. I., Samitz M. H.: Cutaneous signs of cryoparaproteinemia: control with burst Alkeran and Prednisone - Amer. J. Med. 55, $211,1973$. 
14. Brouet J.-C., Clauvel J.P., Danon F., Ki.ein M., Seligmann M.: Biologic and clinical significance of cryoglobulins. A report of 86 cases - Amer. J. Med. 5;.775, 1974.

15. Caulin-Glaser T., Preli.r F., Franklin E. C.: Structural studies on an IgM. $\lambda$ pyroglobulin - J. Lab. clin. Med. 99, 845, 1982.

16. Christian C. L., Hatfield W. B., Chase P. H.: Systemic lupus erythematosus. Cryoprecipita. tion of sera $\cdot \mathrm{J}$, clin. Invest. $12,823,1963$.

17. Cream J. J.: Cryoglobulins in vasculitis - Clin. exp. Immunol. 10. 117, 1972.

18. Cummings N. A.: Studies on cryoglobulins: structural alterations at decreased temperature . Arthr. and Rheum. 12, 661, 1969.

19. Dammacco F., Carandente F.. Vacca A., Campobasso N., Bonomo L.: The occurrence of plasma fibronectin in mixed cryoglobulins from patients with liver cirrhosis - Front gastrointest. Res. 8, 135, 1984.

20. Dammacco F., Gallo G.: Fibronectin is a regular component of single type and mixed cryoglobulins. In: Martinus Nijhoff Publ.: Antiglobulins, cryoglobulins and glomerulonephritis, 1986. (In press).

21. Dammacco F., Lugivero G., Miglietra A., Antonaci S., Bonomo L.: Crioglobulinemia: un modello di malattia da immunocomplessi. Studi immunochimici e strutturali - La Ricerca Clin. Lab. 4, 569, 1974.

22. Dammacco F., Scarpioni L., Antonaci S., Bonomo L.: Cryoimmunoglobulinemia in four sis ters - Acta haematol. (Basel) 59, $215,1978$.

23. Doe W. F., Evans D., Hobrs J. R., Booth C. C.: Coeliac disease, vasculitis and cryoglobulinemia - Gut 13,112,1979.

24. Drüeke T., Barnabel C., Jungers P., Digeon M., Polsson M., Brivet F., Trecan G., Feldmann G., Crosnier J., BACH J. F.: Hepatitis B antigen-associated periarteritis nodosa in patients undergoing long-term hemodialysis - Amer. J. Med. 68, 86, 1980.

25. Emori H. W., Bluestone R., Goldberg L. S.: Pseudo-leukocytosis associated with cryoglobulinemia - Amer. J. clin. Pathol. 60, 202, 1973.

26. Farivar M., Wands J. R., Benson G. D., Dienstag J. L., Isselbacher K. J.: Cryoprotein complexes and peripheral neuropathy in a patient with chronic active hepatitis - Gastroenterology $71,490,1976$.

27. Gallan J. L., Blumberg S. P., Kimber C. L.: Chronic polymyositis: complete heart block and cryoglobulinemia - Aust. N.Z. J. Med. $l, 41,1974$.

28. GALLI M., InYERnizzi F.: Hepatitis B virus and essential mixed cryoglobulinemia - Ann. intern. Med. 95, 522, 1981.

29. GAMBle C. N., Ruggles S. W.: The immunopathogenesis of glomerulonephritis associated with mixed cryoglobulinemia - New Engl. J. Med. 299, 81, 1978.

30. Garcia-Fuentes M., Chantler C., Williams D. G.: Cryoglobulinemia in Henoch-Schönlein purpura - Brit. med. J. ii, 163, 1977.

31. Geltner D., Franklin E. C., Frangione B.: Anti-idiotypic activity in the IgM fractions of mixed cryoglobulins - J. Immunol. 125, 1530, 1980.

32. Gorevic P. D., Kassab H. J., Levo Y., Kohn R., Meltzer M., Prose P., Franklin E. C.: Mixed cryoglobulinemia. Clinical aspects and long-term follow up of 40 patients - Amer. J. Med. $69,287,1980$.

33. Grey H. M., Kohler P. F.: Cryoimmunoglobulins - Semin. Haematol. 10, 87, 1973.

34. Griffiths L. L., Gilchrist L.: Cryoglobulinemia in alcoholic cirrhosis - Lancet $i, 882,1953$.

35. HARDIN J. A.: Cryoprecipitogogue from normal serum: mechanism for cryoprecipitation of immune complexes - Proc. nat. Acad. Sci. (Wash.) 78, 4562, 1981.

36. HeRd Z. L.: Experimental cryoglobulinemia. Production and properties of Streptococcusinduced rabbit cryoglobulins - Immunology 25, 931, 1973.

37. Hutsman J. H. T., van der Wal B., Groen A., van deR Sar A.: Investigations on a heat coagulable globulin in the blood of a patient with multiple myeloma - Clin. chim. Acta 525, $1,1956$. 
38. Hurwitz D. A., Quismorio F. P., Friou G. J.: Cryoglobulinemia in patients with infectious endocarditis - Clin. exp. Immunol. 19, 131, 1975.

39. Husson J. M., Druet P., Contet A., Fiessinger J. M., Cammiller J. P.: Systemic sclerosis and cryoglobulinemia - Clin. Immunol. Immunopathol. 6, 77, 1976.

40. Invernizzi F., Cattaneo R., Rosso di San Secondo V., Balestrieri G., Zanussi C.: Pyroglobulinemia. A report of eight patients with associated paraproteinemia - Acta haematol. (Basel) 50, 65, 1973.

41. Invernizzi F., Pioltelli P., Cattaneo R., Gavazzeni V., Borzini P., Monti G., Zanussi C.: A long-term follow up study in essential cryoglobulinemia - Acta haematol. (Basel) 61, 93, 1979.

42. Krivo J. M., MILler F.: Immunopathology of epidermolysis bullosa acquisita: association with mixed cryoglobulinemia - Arch. Dermatol. 114, 1218, 1978.

43. LAssus A.: Development of rheumatoid factor activity and cryoglobulins in primary and secondary syphilis - Int. Arch. Allergy 36, 515, 1969.

44. Lassus A., Mustakaldo K. K., Wager O.: Autoimmune serum factors and IgA elevation in lymphogranuloma venereum - Ann. clin. Res. 2, 51, 1970.

45. LeRnER A. B., WATSON C. J.: Studies of cryoglobulins. I. Unusual purpura associated with the presence of a high concentration of cryoglobulin (cold-precipitable serum globulin). Amer. J. med. Sci. 214, 410, 1947

46. Levo Y., Gorevic P. D., Kassab H. J., Zucker-Franklin D., Franklin E. C.: The association between hepatitis B virus and essential mixed cryoglobulinemia - New Engl. J. Med. 296, $1501,1977$.

47. Liss M., Fudenberg H. H., Kritzman J.: A Bence Jones cryoglobulin: chemical, physical and immunological properties - Clin. exp. Immunol. 2, 467, 1967.

48. London W. T.: Hepatitis B virus and antigen-antibody complex diseases - New Engl. J. Med. $296,1528,1977$.

49. LoSpalluto J., Dorward D., Miller W., Ziff M. Jr.: Cryoglobulinemia based on interaction between a gamma-macroglobulin and $7 S$ gamma-globulin-Amer. J. Med. 32, 142, 1962.

50. Martin W.J., Mathieson D. R.: Pyroglobulinemia. Heat coagulable globulin in the blood Mayo Clin. Proc. 28, 545, 1953.

51. Martin W. J., Mathieson D. R.. Eigler J. O.: Pyroglobulinemia: further observations and re. view of 20 cases - Mayo Clin. Proc. 34, 95, 1959.

52. McCann S. R., Zinneman H. H., Oken M. M., Leary M. C., Swam W. R., Moore M.: IgM py. roglobulinemia with erythrocytosis presenting as hyperviscosity syndrome. I. Clinical fea tures and viscometric studies - Amer. J. Med. 61, 316, 1976.

53. McIntosh R. M., Kauffman D. B., Kulvinskas C., Grossman B. J.: Cryoglobulins. I. Studies on the nature, incidence and clinical significance of serum cryoproteins in glomerulonephri tis - J. Lab. clin. Med. 75, 566, 1970.

54. McIntosh R. M., Koss M. N.. Gocke D. J.: The nature and incidence of cryoproteins in hepati tis $B$ antigen (HBsAg) positive patients - Quart. J. Med. 45, 23, 1976.

55. Meltzer M., Franklin E. C.: Clyoglobulinemia. A study of 29 patients. I. IgG and IgM cryoglobulins and factors affecting cryoprecipitability - Amer. J. Med. 40, 828, 1966.

56. Meltzer M., Franklin E. C., Elias K., MCCluskey R. T., Cooper N.: Cryoglobulinemia. A clinical and laboratory study. II. Cryoglobulins with rheumatoid factor activity - Amer. J. Med. 40, 837, 1966.

57. Meroni P. L., Barcelling W., Messina C., De Bartolo G., Capsoni F., Invernizzi F.: Defective suppressor cell activity in essential mixed cryoglobulinemia $\cdot \mathrm{J}$. clin. Lab. Immunol. 8, 177 , 1982.

58. Middaugh C. R., Kehoe G. M., Prystowsky M. B., Gerber.Jenson B., Jenson J. C., Litman G. W.: Molecular basis for the temperature-dependent insolubility of cryoglobulins. IV. Struc. tural studies of the IgM monoclonal cryoglobulin McE - Immunochemistry 15, $171,1978$.

59. Miyagawa S., SAKamoto K.: Characterization of cryoprecipitates in pemphigus. Demonstration of pemphigus antibody using the IF technique - J. invest. Dermatol. 69, 373, 1977. 
60. Monteverde A.: Le crioglobulinemie miste. In: Atti $84^{\circ}$ Congr. Soc. Ital. Med. Int. Milano, $5 \cdot 8$ ottobre 1983. L. Pozzi ed.. Roma, 1983; p. 355.

61. Mookerjee B. K., Madotsox P. J., Richlin M.: Mesangial IgA-IgG deposition in mixed cryoglobulinemia - Amer. J. med. Sci. 276, 221, 1978.

62. Most H., Lavietes P. H.: Kala-azar in American military personnel: report of 30 cases Medicine (Baltimore) 26, 221, 1947.

63. Nightingale S. D., Pelley R. P., Del.aney N. L.. Bias W. B., Hamburger M. I., Fries L. F., Sternberc A. G.: Inheritance of mixed cryoglobulinemia . Amer. J. hum. Genet. 33, 735, 1981.

64. Ottò S., Szantò J., Borzsonyı M., Kocsis G. Y.: Monoclonal cryoimmunoglobulinemia of IgG $_{4}$ subclass specificity - Oncology 40, 205, 1983.

65. Patterson R., Roberts M.. Rambach W., Falleroni A.: An IgM pyroglobulin associated with lymphosarcoma - Amer. J. Med. 48, 503, 1970.

66. Peters G. A., Horton B. T.: Allergic purpura with special reference to hypersensitivity to cold - Mayo Clin. Proc. 16, 631, 1941.

67. Popp j. W., Dienstag J. L., Wands J. R., Bloch K. J.: Essential mixed cryoglobulinemia with out evidence for hepatitis B virus infection - Ann. intern. Med. 92, 379, 1980.

68. Pruzanski W., Jancelewicz Z., Underdown B.: Immunological and physicochemical studies of $\operatorname{Ig} A 1(\lambda)$ cryoglobulinaemia - Clin. exp. Immunol. 15, 181, 1973.

69. Saha A., Chowdhury P., Sambury S., Smart K., Rose B.: Studies on cryoprecipitation. IV. En zymic fragments of a human cryoglobulin - J biol. Chem. 245, 2730, 1970.

70. SALUK P. H., CLEM W.: Studies on the cryoprecipitation of a human $\operatorname{IgG}_{3}$ cryoglobulin: the ef fects of temperature-induced conformational changes on the primary interaction - Immunochemistry $12,29,1975$.

71. SCARLeTt J. A., Kistner M. L., YANG L. C.: Behceet's syndrome: report of a case associated with pericardial effusion and cryoglobulinemia treated with indomethacin - Amer. J. Med. 66, $146,1979$.

72. Schifferli J. A., Amos N., Pusey C. D., Sissons J. G. P., Peters D. K.: Metabolism of IgG in type II mixed essential cryoglobulinemia. Autologous cryoprecipitated and normal homologous IgG are incorporated into complexes and metabolized in vivo at similar rates - Clin. exp. Immunol. 51, 305, 1983.

73. Schimmer B. M., Block K. J.: Mixed IgG.IgM cryoglobulinemia terminating in polyarteritis nodosa $\cdot J$. Rheumatol. 2, 241, 1975.

74. Selicmann M., Danon F., Basch A., Bernard J-: IgG myeloma cryoglobulin with antistreptolysin activity - Nature (Lond.) 220,711, 1968.

75. Shusterman N., London W. T.: Hepatitis B and immune complex disease - New Engl. J. Med. $310,43,1984$.

76. Stoebner P., Renversez J.C.. Groulade J., Vialtel P., Cordonier D.: Ultrastructural study of human IgG and IgG.IgM crystalcryoglobulins - Amer. J. clin. Pathol. 71, 404, 1979.

77. Strevey J., Beaulieu A. D., Menard C. Valer J.-P., Latulippe L., Hebert J.: The role of fi. bronectin in the cryoprecipitation of monoclonal cryoglobulins . Clin. exp. Immunol. 55, 340, 1984.

78. Sugar S.: IgA pyroglobulin, hyperviscosity syndrome and coagulation abnormalities in a patient with inultiple myeloma. Blood 224, 39, 1972.

79. Turkington R. W., Buckley C. E.: Macrocryoglobulinemia in Henoch-Schönlein purpura . Brit. med. J. ii, $163,1977$.

80. Ukı J., Younc C. A., SUzukı T.: A 22 S cryomacroglobulin with antibody-like activity. Physicochemical characterization and modification of its cryoproperties - Immunochemistry 11,729 , 1974.

81. Wager O., Mustakallio K. K., RÄSÄnen J. A.: Mixed IgA-IgG cryoglobulinemia: immunological studies and case reports of 3 patients - Amer. J. Med. 44, 179, 1968.

82. Wager O., RÄSÄNen J. A., Hagman A., Klemola E.: Mixed cryoglobulinemia in infectious mononucleosis and cytomegalovirus mononucleosis - Int. Arch. Allergy 34, 345, 1968. 
83. Wands J. R., Dienstag J. L., Bhan A. T., Feller E. R., Isselbacher K. J.: Circulating immune complexes and complement activation in primary biliary cirrhosis - New Engl. J. Med. 298, $233,1978$.

84. Wang A. C., Wells J. V., Fudenberg H. H., Gergely J.: Chemical analyses of cryoglobulins . Immunochemistry $11,341,1974$.

85. Watanabe A., Kitamura M., Shimizu M.: Immunoglobulin A ( $\operatorname{Ig}$ A) with properties of both cryoglobulin and pyroglobulin - Clin. chim. Acta 52, $231,1974$.

86. WEISMAN M., ZVAIFLER N.: Cryoimmunoglobulinemia in rheumatoid arthritis. Significance in serum of patients with rheumatoid vasculitis - J. clin. Invest. 56, 725, 1975.

87. Wilson M. R., Arroyave C. M., Miles L., TAN E. M.: Immune reactants in cryoproteins. Rela tionship to complement activation - Ann. rheum. Dis. 36, 540, 1977.

88. Wintrobe M. M., BUEll M. V.: Hyperproteinemia associated with multiple myeloma; with report of a case in which an extraordinary hyperproteinemia was associated with thrombosis of the retinal veins and symptoms suggesting Raynaud's disease - Bull. Johns Hopk. Hosp. 52, 156, 1933.

89. Wood G., Rucker M., DAvis J. M., Entwistle R., ANDERSEn B.: Interaction of plasma fibro nectin with selected cryoglobulins - Clin. exp. Immunol. 40, 358, 1980.

90. ZANUSSI C: Le crioglobulinemie miste essenziali: un modello di ricerca immunoclinica. In: Atti IV Congr. Soc. Ital. Immunol. Immunopatol., Firenze, 1980; p. 107.

91. ZINNEMAN H. H., CAPERTON E.: Cryoglobulinemia in a patient with Sjögren's syndrome, and factors of cryoprecipitation - J. Lab. clin. Med. 89, 483, 1977.

92. Zinneman H. H., Levi D., SeAl U. S.: On the nature of cryoglobulins - J. Immunol. 100, 594, 1968.

Requests for reprints should be addressed to:

Franco Dammacco

Istituto di Patologia Medica

Università degli Studi di Bari, Policlinico

Viale Ennio, 70124 Bari - Italia 